\title{
Barriers Towards Research Among Medical Students ${ }^{1}$ Paras Khan, ${ }^{2}$ Muhammad Faheem Afzal, ${ }^{2}$ Muhammad Haroon Hamid, ${ }^{3}$ Asif Hanif ${ }^{1}$ Department of Ophthalmology, Mayo Hospital, Lahore \\ ${ }^{2}$ Department of Pediatrics, King Edward Medical University, Lahore \\ ${ }^{3}$ Department of Biostatics, University Institute of Public Health, University of Lahore
}

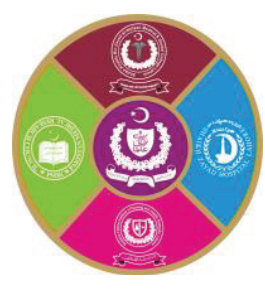

\begin{abstract}
Introduction: Scientific publications by the undergraduate students reflect their level of critical thinking, and attitude and skill regarding research. Students are indeed very motivated to do research, but are hindered by some barriers. Aims \& Objectives: To determine the barriers towards research among medical students. Place and duration of study: This cross sectional survey was conducted in King Edward Medical University, Lahore from May to October 2018. Material \& Methods: Through non-probability convenient sampling, 275 students were asked to fill a Likert scale type questionnaire, enumerating research barriers, after ensuring their confidentiality and anonymity. Statistical Package for Social Sciences version 22 was used for analyzing the data which was presented as frequency tables. Results: Total number of respondents was 275 with female to male ratio of 1.6:1. Lack of experience $(223,83 \%)$, lack of knowledge about research methodology $(211,76.7 \%)$, deficient guidance by teachers $(180,65.5 \%)$, non-availability of a skilled librarian $(194,70.6 \%)$, lack of appropriate diagnostic facilities $(184,66.9 \%)$, lengthy synopsis approval process by ethical review board $(188,68.4 \%)$, and peer review by publishing journal $(183,66.5 \%)$, lack of funding $(160,58.2 \%)$, and lack of research culture in society $(216,78.5 \%)$ were considered as barriers. Conclusion: The undergraduate medical students considered lack of knowledge about research methodology and statistics, deficient guidance by teachers, lack of funding and appropriate diagnostic facilities, lengthy synopsis approval process by ERB, peer review by publishing journal and lack of research culture in society as barriers to research.
\end{abstract}

Key words: Medical students, Barriers, Research

\section{INTRODUCTION}

$\mathrm{R}$ Research is a systematic process that uses standard methods to achieve new knowledge, science or invention. In this age of evidence based practice, there is much emphasis on inculcating research culture in undergraduate medical curriculum, so that medical students may become better clinical practitioners in future and improve patient care. ${ }^{1}$ Scientific publications by the undergraduate students of a country reflect their level of critical thinking and attitude in research. Moreover, research experience and subsequent publications increase the chances of acceptance of medical students in highly competitive post graduate training programs. ${ }^{2}$

Studies have reported that students are indeed very motivated to do research, but are being held back by a number of barriers. ${ }^{3}$ These barriers are posed by personal lacking, organizational mismanagement, financial deprivation and even the general attitude of a society toward research. ${ }^{4}$ Lack of encouragement and guidance from mentors about research, lack of facilities and sources of literature, hefty curriculum, ${ }^{5,6}$ lack of funding, ${ }^{7}$ little practical impact on society, ${ }^{8}$ and generalized negative attitude shown by their supervisors to younger researchers ${ }^{9,10}$ are considered as potential barriers to research.

In Pakistan, the research culture is just developing among undergraduates. Studies identifying barriers among them have also been few. So this study will help to determine the barriers that are preventing the practice of quality research among medical undergraduates.

\section{MATERIAL AND METHODS}

This cross sectional survey was conducted in King Edward Medical University, Lahore from May to October 2018. This study was approved from the institutional review board. The study instrument used was a questionnaire enumerating barriers to 
research for students. This Likert scale type questionnaire had 4 domains and 34 items. The participants were briefed about the study and were assured of their confidentiality and anonymity. Students' responses were recorded according to the Likert Scale for each question (strongly disagree, disagree, neutral, agree and strongly agree). The responses of students who did not want to participate in the survey and those who did not answer three or more questions were excluded from the study.

\section{Statistical analysis:}

SPSS 22 was used for statistical analysis of the data and was presented as frequency tables. Chi square test was applied for comparative analysis between the three classes.

\section{RESULTS}

Total number of respondents was 275 out of which $169(61.5 \%)$ were female students with female to male ratio of $1.6: 1$. Respondents who had studied previously in matriculation system were $80.4 \%(\mathrm{n}=$ 221) and those from Cambridge Assessment International Education (CAIE) system were 19.6\% $(\mathrm{n}=54)$. Participants from third, fourth and final year were 87 (31.6\%), $125(54.5 \%)$ and 63 (22.9\%) respectively. (Table-1)

The barriers were divided into four domains: individual, organizational, financial and social. For the purpose of simplicity, we took strongly agree and agree as positive response. Lack of previous experience in research $(223,83 \%)$, recognition of areas that needed research $(213,77.5 \%)$, lack of knowledge about research methodology (211, $76.7 \%$ ), lack of knowledge about statistics (203, $73.8 \%$ ), insufficient knowledge of publication criteria $(208,75.6 \%)$, no previous participation in any research program $(200,72 \%)$ were potential individual barriers (Fig-1). Deficient guidance by teachers $(180,65.5 \%)$, non-availability of a skilled librarian who could help in finding relevant literature $(194,70.6 \%)$, lack of appropriate diagnostic facilities $(184,66.9 \%)$, not enough credit given to students after the completion of research $(175,63.7 \%)$, lengthy process of approval of synopsis by Ethical Review Board (188, 68.4\%), delay in approval of article by supervisor (189, $68.7 \%$ ), and peer review by publishing journal (183, $66,5 \%)$ were considered as organizational barriers (Fig-2). Lack of funding $(160,58.2 \%)$, lack of research culture in society $(216,78.5 \%)$ were financial and socio-cultural barriers (Fig-3).

Comparing the responses between different classes, it was found that final year MBBS, who have passed through research has overall more agreement on barriers than $3^{\text {rd }}$ and $4^{\text {th }}$ year (Table-2).

\begin{tabular}{|l|l|l|}
\hline \multicolumn{2}{|c|}{ Variables } & \multicolumn{1}{c|}{ n (\%) } \\
\hline \multirow{2}{*}{ Gender } & Male & $106(39.5)$ \\
\cline { 2 - 3 } & Female & $169(61.5)$ \\
\hline \multirow{2}{*}{$\begin{array}{l}\text { Educational } \\
\text { Background }\end{array}$} & Matric/F.Sc. & $221(80.4)$ \\
\cline { 2 - 3 } Year of study & GSCE & $54(19.6)$ \\
\cline { 2 - 3 } & $3^{\text {rd }}$ Year & $87(31.6)$ \\
\cline { 2 - 3 } & $4^{\text {th }}$ Year & $125(45.5)$ \\
\cline { 2 - 3 } Total & & $63(22.9)$ \\
\hline Tinal Year & $275(100)$ \\
\hline
\end{tabular}

Table-1: Distribution of cases by Gender, educational background \& Year of study $(n=275)$

\begin{tabular}{|c|c|c|c|c|c|c|}
\hline \multirow{2}{*}{$\begin{array}{l}\text { Year of MBBS in } \\
\text { which respondent } \\
\text { is studying (I) }\end{array}$} & \multirow{2}{*}{$\begin{array}{l}\text { Year of MBBS in } \\
\text { which respondent } \\
\text { is studying }(J)\end{array}$} & \multirow{2}{*}{$\begin{array}{l}\text { Mean } \\
\text { Difference (I-J) }\end{array}$} & \multirow{2}{*}{$\begin{array}{l}\text { Std. } \\
\text { Error }\end{array}$} & \multirow[t]{2}{*}{ Sig. } & \multicolumn{2}{|c|}{ 95\% Confidence Interval } \\
\hline & & & & & $\begin{array}{l}\text { Lower } \\
\text { Bound }\end{array}$ & $\begin{array}{l}\text { Upper } \\
\text { Bound }\end{array}$ \\
\hline \multirow[t]{2}{*}{ Third year } & Fourth year & 1.64818 & 2.48632 & .508 & -3.2467 & 6.5431 \\
\hline & Final year & $-13.60591^{*}$ & 2.94591 & .000 & -19.4056 & $\begin{array}{l}-7.8062 \\
\end{array}$ \\
\hline \multirow[t]{2}{*}{ Fourth year } & Third year & -1.64818 & 2.48632 & .508 & -6.5431 & 3.2467 \\
\hline & Final year & $-15.25410^{*}$ & 2.75143 & .000 & -20.6709 & -9.8373 \\
\hline \multirow[t]{2}{*}{ Final year } & Third year & $13.60591^{*}$ & 2.94591 & .000 & 7.8062 & 19.4056 \\
\hline & Fourth year & $15.25410^{*}$ & 2.75143 & .000 & 9.8373 & 20.6709 \\
\hline
\end{tabular}

Table-2: Multiple Comparisons on total score $(n=275)$

(Chi-square test was applied) 


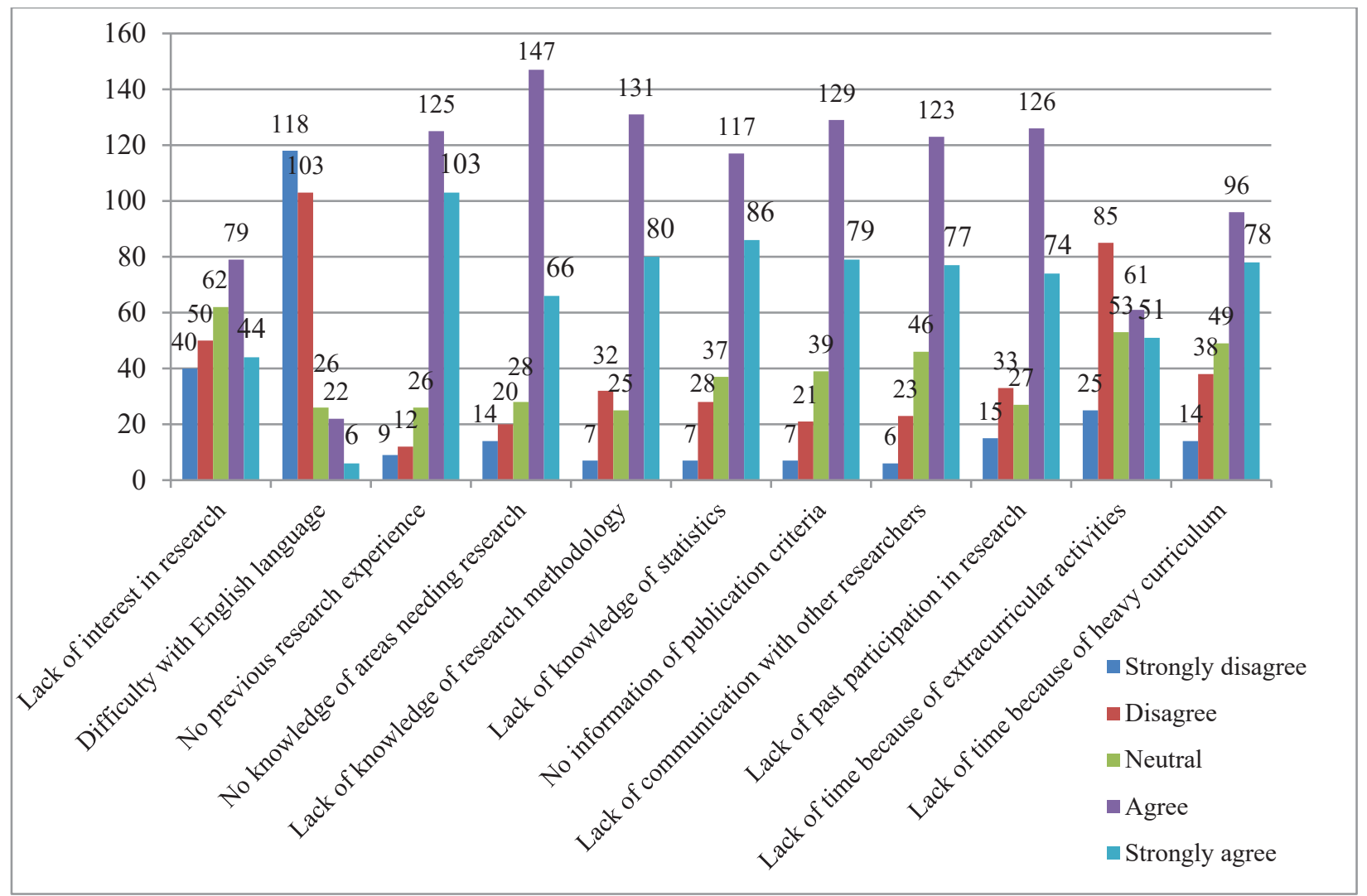

Fig-1: Frequency of Individual Barriers towards Research

$(n=275)$

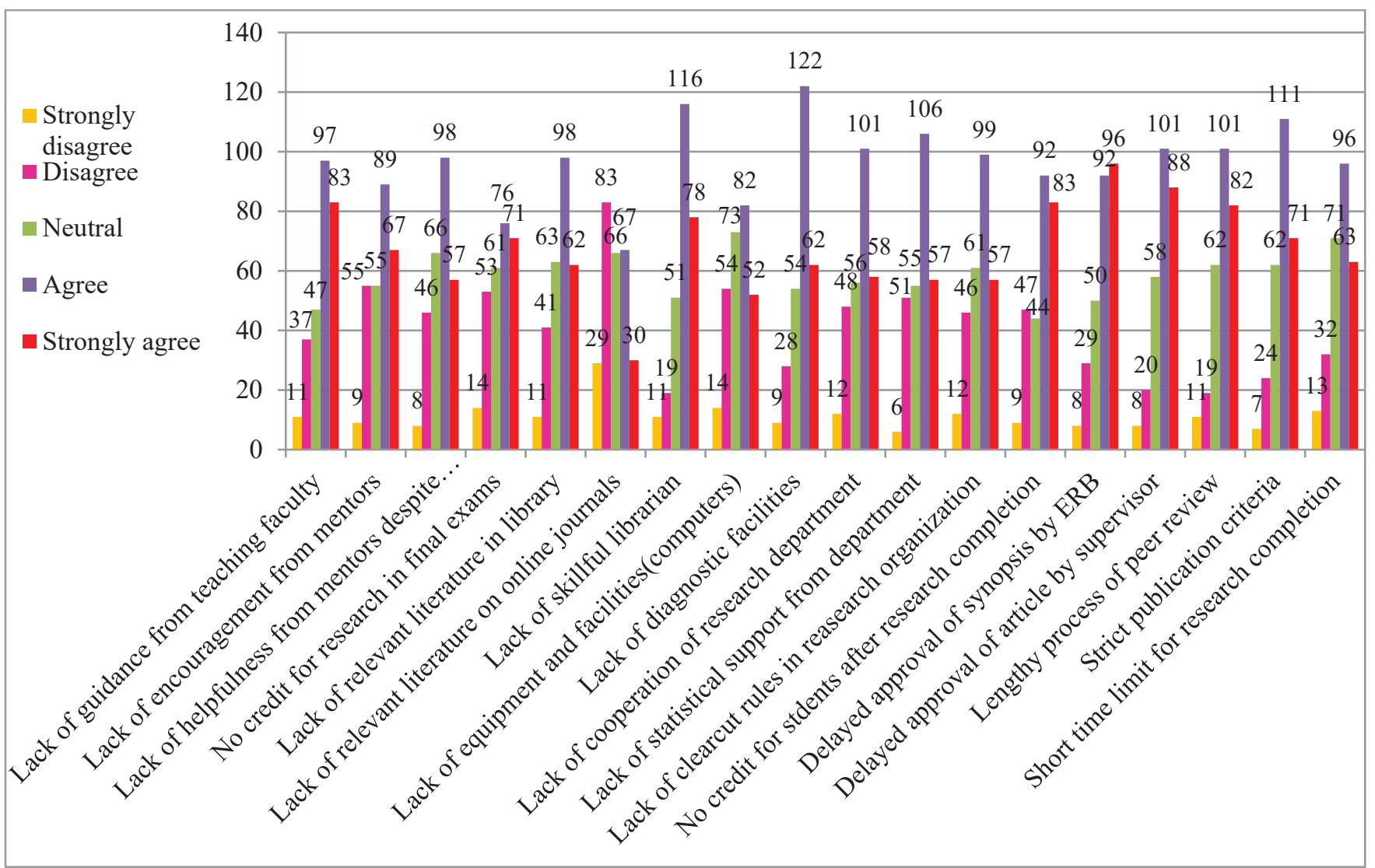

Fig-2: Frequency of Organizational Barriers towards Research $(n=275)$ 


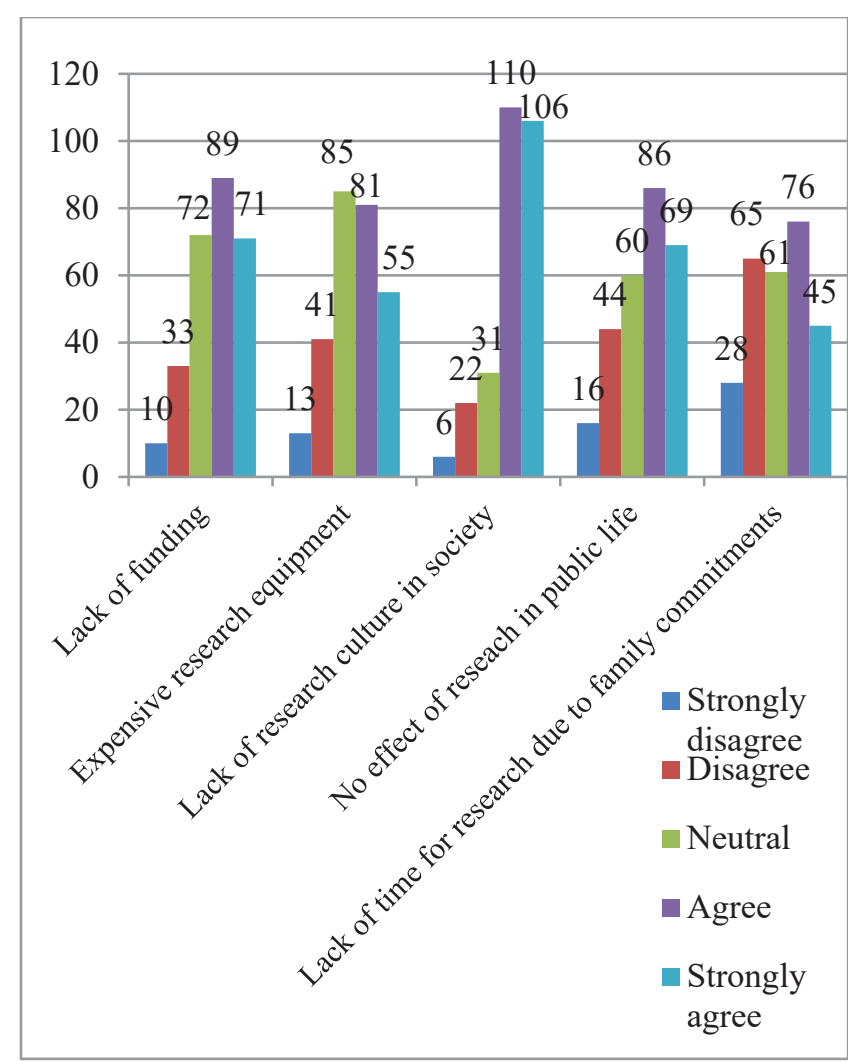

Fig-3: Frequency of Financial \& Socio-Cultural Barriers towards Research $(n=275)$

\section{DISCUSSION}

Medical undergraduates face a plethora of barriers when it comes to participation in research. In the present study, $83 \%$ students considered lack of previous experience in research, while $76 \%$ students considered lack of knowledge about research methodology as barrier to research. Our results are supported by local data from Raza et $\mathrm{al}^{2}$ who also observed lack of interest, lack of training in scientific literature and research methodology as barriers. The barriers reported by us are similar to those reported in international literature. ${ }^{11,12,13}$ These barriers might be tackled if students are provided with comprehensive and high quality books written by well versed researchers and mentors on the basics of research. Increasing the span of compulsory research projects over more than just one year (4th year) will likely help in building up the pupils' research experience.

Deficient guidance by teachers $(65.5 \%)$, lack of appropriate diagnostic facilities $(66.9 \%)$, lack of enough credit $(63.7 \%)$, lengthy process by publishing journal $(66,5 \%)$, lack of funding (160 $(58.2 \%)$, lack of research culture in society $(216(78.5 \%)$ were also potential barriers. Our results are comparable with a local study by Raza et ${ }^{2}$ al and Meraj et $\mathrm{al}^{11}$ showing institutional barriers as most common barriers to participation in research. Same was reported by Al-Ghamdi et $\mathrm{al}^{5}$ and Al-Shalawy et $\mathrm{al}^{12}$ in which lack of professional supervision, and lack of training were different institutional barriers. Memarpour et $\mathrm{al}^{1}$ also cited financial inadequacy as the main barrier as did some other previous studies. ${ }^{14,15}$ The financial limitation might be overcome if the institutes try to dwell not just on the government for research funding but also on nongovernmental sources. Researchers should also be encouraged to strive for grants and awards. Concerning the inadequate diagnostic facilities, if students are allowed access to the data of diagnostic laboratories within the institute, they might be able to do retrograde research studies on already available diagnostic information. It might be made mandatory for the clinical consultants and researchers to include a particular number of volunteering medical students as part of their research team. It will help inculcate a positive attitude in medical society towards research.

There exist several limitations to this study that need to be taken into account. Firstly, this study is a selfreport survey and independent verification of data could not be done. Secondly, students of only one medical university were included in the survey and results may not be representative of other institutes. Finally, only volunteer students filled the questionnaires and complete attendance in classes could not be managed at the time of survey. The results also suggest formulating measures to alleviate individual, organizational, financial and social barriers so that research can flourish in our medical undergraduates.

\section{CONCLUSION}

This study concluded that undergraduate medical students consider lack of knowledge about research methodology and statistics, deficient guidance by teachers, lack of funding and appropriate diagnostic facilities, lengthy process of approval of synopsis by ethical review board and peer review by publishing journal and lack of research culture in society as barriers to research.

The take home message is that the alleviation of these barriers demands work on part of not only the students but also the medical institute as a whole. Arrangements should be made to employ only well versed supervisors, organize precise and high yield research workshops for students, provide access to quality online literature to students and increase their access to clinical and laboratory data. Moreover, the students should be encouraged to voice their concerns openly because only then the 
barriers they are facing can be recognized and dealt with.

\section{Acknowledgements}

The authors highly acknowledge the $3^{\text {rd }}, 4^{\text {th }}$, and final year MBBS students of King Edward Medical University, Lahore, who volunteered to be a part of the survey.

\section{REFERENCES}

1. Memarpour M, Fard AP, Ghasemi R. Evaluation of attitude to, knowledge of and barriers toward research among medical science Students. Asia Pac Fam Med 2015; 14:1.

2. Raza F, Nisa Q. Perception, attitudes and barriers in undergraduate medical students toward medical research at Rehman medical college, Peshawar, Pakistan. Khyber Med Univ J 2017; 9(3):146-9.

3. Noorelahi MM, Soubhanneyaz AA, Kasim KK. Perceptions, barriers, and practices of medical research among students at Taibah College of Medicine, Madinah, Saudi Arabia. Adv Med Educ Pract 2015; 6:479-85.

4. Al-Halabi B, Marwan Y, Hasan M, Alkhadhari S. Extracurricular research activities among senior medical students in Kuwait: experiences, attitudes, and barriers. Adv Med Educ Pract 2014; 5:95-101.

5. Alghamdi KM, Moussa NA, Alessa DS, Alothimeen N, Al-Saud AS. Perceptions, attitudes and practices toward research among senior medical students. Saudi Pharm J 2014; 22(2):113-7.

6. Pawar DB, Gawde SR, Marathe PA. Awareness about medical research among resident doctors in a tertiary care hospital: a cross-sectional survey. Perspect Clin Res 2012; 3(2):57-61.

7. De Oliveira NA, Luz MR, Saraiva RM, Alves LA. Student views of research training programmes in medical schools. Med Educ 2011; 45(7):748-55.

8. Ejaz K, Shamim M, Shamim M, Hussain S. Involvement of medical students and fresh medical graduates of Karachi, Pakistan in research. J Pak Med Assoc 2011; 61(2):115-20.

9. Khan H, Khan S, Iqbal A. Knowledge, attitudes and practices around health research: the perspective of physicians-in-training in Pakistan. BMC Med Educ 2009; 9:46.

10. Khan H, Khawaja R, Waheed A, Rauf M, Fatmi Z. Knowledge and attitudes about health research amongst a group of Pakistani medical students. BMC Med Educ 2006; 6:54.

11. Meraj L, Gul N, Zubaidazain IA, Iram F, Khan AS. Perception and Attitude towards research amongst medical students at Shifa College of Medicine. J Pak Med Assoc 2016; 66(2):165-9.

12. Al-Shalawy FAN, Haleem A. Knowledge, attitudes and perced barriers towards scientific research among undergraduate health sciences students in the Central Province of Saudi Arabia. Educ Med J 2015; 7(1):16-21.

13. Siemens DR, Sanoj P, James W, Nimira K. A survey on the attitudes towards research in medical school. BMC Med Educ. 2010; 10:4.

14. Amin T, Kaliyadan F, Abdulatheem EA, Majed M, Khanjaf H, Mirza M. Knowledge, attitudes and barriers related to participation of medical students in research in three Arab Universities. Educ Med J 2012; 4(1):e47-e 55.

15. Burgoyne LN, O'Flynn S, Boylan GB. Undergraduate medical research: the student perspective. Med Educ Online 2010; 10:15.

\section{The Authors:}

Dr. Paras Khan,

House Officer,

Ophthalmology,

Mayo Hospital, Lahore.

Dr. Muhammad Faheem Afzal,

Associate Professor,

Department of Pediatrics,

King Edward Medical University, Lahore.

Prof. Muhammad Haroon Hamid,

Department of Pediatrics,

King Edward Medical University, Lahore.

Dr. Asif Hanif,

Associate Professor,

Department of Biostatistics,

University Institute of Public Health,

University of Lahore.

\section{Corresponding Author:}

Dr. Paras Khan,

House Officer,

Ophthalmology,

Mayo Hospital, Lahore.

E-mail:khan_paras@hotmail.com 